\title{
Determination of the Surface Roughness Parameter and Wind Shear Exponent of Kisii Region from the On-Site Measurement of Wind Profiles
}

\author{
Ongaki N. Laban $\mathbb{D}^{1},{ }^{1}$ Christopher M. Maghanga, ${ }^{2}$ and Kerongo Joash ${ }^{3}$ \\ ${ }^{1}$ Department of Physics, Kisii University, Kenya \\ ${ }^{2}$ Department of Mathematics and Computing Science, Kabarak University, Kenya \\ ${ }^{3}$ Department of Mathematics and Actuarial Sciences, Kisii University, Kenya \\ Correspondence should be addressed to Ongaki N. Laban; labanongaki@yahoo.com
}

Received 16 April 2019; Accepted 12 June 2019; Published 1 July 2019

Academic Editor: Guobing Zhou

Copyright (C) 2019 Ongaki N. Laban et al. This is an open access article distributed under the Creative Commons Attribution License, which permits unrestricted use, distribution, and reproduction in any medium, provided the original work is properly cited.

\begin{abstract}
The research sought to investigate the surface roughness parameter $\left(Z_{o}\right)$ and wind shear exponent $(\alpha)$ of Kisii region (elevation $1710 \mathrm{~m}$ above sea level, $0.68^{\circ} \mathrm{S}, 34.79^{\circ} \mathrm{E}$ ). A six-month experiment was set at three sites of Kisii region. Two PRO AcuRite 01036 Wireless Weather Stations with pro+ 5-in-1 Sensors were placed at different hub heights above the ground and data were sent and received by a display board set at a room through remote sensing at an interval of 12 minutes. Data was collected from the display board through the pc connect software, grouped into discrete data and then calculated to represent mean wind speed, diurnal variation, daily variation, and monthly variations. The calculated averages of wind speeds at hub heights of $10 \mathrm{~m}$ and $13 \mathrm{~m}$ were then used to determine the wind shear exponent and surface roughness parameter of the sites. The wind shear exponents were found to be $0.92,0.41$, and 0.54 for Nyamecheo, Kisii University, and Ikobe stations, respectively, with an average of 0.64 . The roughness parameter was also calculated and found to be 3.75, 1.32, and 1.96 for Nyamecheo, Kisii University (KSU), and Ikobe, respectively, with an average of 2.35 .
\end{abstract}

\section{Introduction}

The chief economic determinant of the operation of any wind power plant is the availability of enough wind speed which can be measured directly in a certain hub height or by use of extrapolating methods to higher heights based on known lower hub height. To extrapolate, proper knowledge of shear trend and roughness parameter is necessary. The surface roughness parameter $z_{0}$ is defined as the height above the surface at which wind speed goes to zero if the turbulent layer extends completely to the ground [1]. Wind speed near the ground is influenced by topographical features and atmospheric temperature stratification which causes wind shear variation per hour, month, and season [2,3]. Although associated with uncertainties, the power law and logarithmic law are the most commonly used in the calculations of the wind shear coefficient and roughness parameters. The power law exponent provides a relationship between mean wind speeds $\left(\bar{v}_{1}, \bar{v}_{z}\right)$ from two different hub heights with the wind shear exponent $(\alpha)$ describing the fetch characteristics of a given site [1]. According to [4], default power law coefficient should be used cautiously for wind energy estimation and in pollutant dispersion analysis under various surface and structure in atmospheric layer. The wind shear exponent $\alpha$ (ranging from 0 to 1 ) gives the best fitting to wind speeds between two reference hub heights with a single value attached to a given surface hence no allowance for variation with height [1]. According to [5], the exponent function $(\alpha)$ increases with surface roughness $\left(Z_{o}\right)$ and decreases with increase in height and incorporate thermal effects upon the vertical wind speed profile.

As wind flows, it undergoes several changes. As a consequence, surface roughness and wind shear exponent parameters also change depending on the topographical features of the place, time of the day, direction of wind, and height above ground. These variations matter in wind speed data and hence 


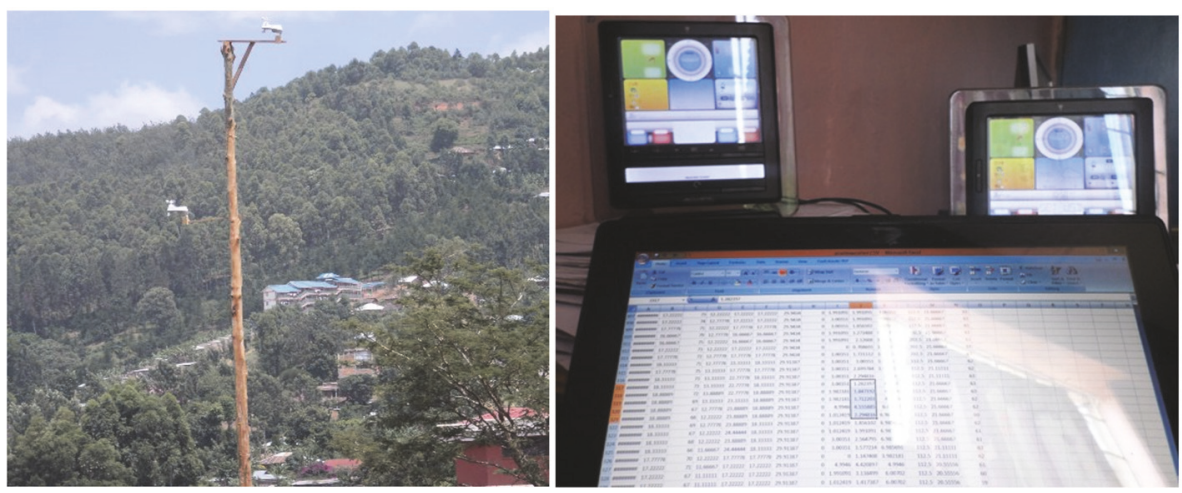

FIgure 1: AcuRite wind sensors display boards and PC at Kisii University.

their extrapolation to higher hub heights should be carefully considered [6]. There is rapid increase in wind speed over short time when surface roughness is small. When surface roughness is large, there is slow and smooth increase in wind speed profiles [4].

The same way wind speed variation curves can be used to predict and map the amount of wind energy in a given location, surface roughness parameter variation curves at a site can also be used to map and predict the expected wind power at various terrains through describing their diurnal, dairy, and seasonal variations. In cases where the roughness parameter of a given terrain fails to fall under any of the roughness parameter class, their averages can then be adopted [7]. Surface roughness parameter helps in characterizing the intensity of turbulence and efficiency of turbulence mixing of heat, moisture, and momentum between the land and atmosphere layer [7].

\section{Materials and Methods}

Kisii University, Nyamecheo, and Ikobe are three stations located in Kisii region which lie along the equator of the western parts of Kenya (elevation $1710,0.68^{\circ} \mathrm{S}, 34.79^{\circ} \mathrm{E}$ ). The sites are invested with small hills and receive rain all year round, something which makes them to be bushy and ever green. Data from the stations was obtained by installing AcuRite weather stations with 5-1 sensors in the stations (Figure 1). Two indoor display boards were set inside the room within a radius of $100 \mathrm{~m}$ from the stations and programmed to receive data from the two stations simultaneously at an interval of 12 minutes each through remote sensing. By use of the PC connect, data received and stored by the indoor display boards was transferred to the computer for analysis. The instruments were set at the sites at two different hub heights $(10 \mathrm{~m}$ and $13 \mathrm{~m})$ and data collected were used to determine the wind shear and roughness parameters of the sites.

Measurement of wind was done by use of the cup anemometer based on the use of the cup wheels. In this weather station, three light plastic trapezoidal cups of dimensions $50 \mathrm{~mm}$ for longer base, $32 \mathrm{~mm}$ for shorter base, and $43 \mathrm{~mm}$ for height mounted symmetrically about a vertical axis at the ends of the same number of arms protruding from the hub of the wheel have been used to measure wind speed. The anemometer works on the principle that since force of the wind is greater on the concave side of the cup in comparison with the convex side, the cup wheel will rotate in the air stream. The machine has been designed in such a way that friction in the bearings of the wheel is low and hence small wind speeds will set the cups into motion.

This cup wheel performs well in a steady wind speed of almost $0.5 \mathrm{~m} / \mathrm{s}$ up to $45 \mathrm{~ms}^{-1}$ with accuracy of $\pm 2.0 \mathrm{~ms}^{-1}$. This made it a suitable choice for measuring wind speeds for the sites which falls within the range. However, in gusty winds, the cup anemometer tends to read a higher average wind speed than the actual one. This is due to the fact that cup wheels possess inertia which makes them accelerate more rapidly under increasing wind speed than it decelerates with decreasing wind speed.

AcuRite weather stations used are accurate and can be maintained from time to time. The following factors were considered for its selection, accuracy in measuring wind speed, difficulty in handling them, stability over a long period of time to minimize need for maintenance work, and the easiness to identify the sources of errors and elimination of them. The AcuRite weather station was tested and found to be accurate in its measurements, difficult to handle, stable over a long period of time though required change of batteries, and above all easy to identify the sources of errors and elimination. Having satisfied all this conditions, the instrument qualified for selection and use.

AcuRite wind sensors are manufactured by Chaney Instrument Co. which is a subsidiary of the Primex Family of Companies (PFOC). It was founded in 1943 and has its headquarters in Lake Geneva, Wisconsin. Since it started the production of these instruments, AcuRite brand weather instruments have earned a long-standing reputation as the leader in precision time, temperature, and weather products. The AcuRite brand whether station is known for its ease of use, reliable quality, precision accuracy, and knowledgeable support team.

\subsection{Governing Equations and Principles}

\subsubsection{The Power Exponent Function}

$$
\frac{V_{y}}{V_{10}}=\left(\frac{Z_{y}}{Z_{10}}\right)^{\alpha}
$$


where $\alpha$ is the wind shear exponent of the region which depends on the roughness of the terrain and can be calculated using

$$
\alpha=\frac{\ln \left(V_{y}\right)-\ln \left(V_{10}\right)}{\ln \left(Z_{y}\right)-\ln \left(Z_{10}\right)}
$$

where

$$
\begin{aligned}
& Z_{y} \text { - height above the ground, } \\
& \overrightarrow{\mathbf{v}_{\mathbf{y}}} \text { - mean wind speeds at height, } Z_{y} \\
& \qquad \overrightarrow{\mathrm{V}_{\mathrm{z}}}=\mathrm{V}_{10} \frac{\ln \left(\overrightarrow{\mathrm{Z}_{\mathrm{y}}} / \mathrm{Z}_{10}\right)}{\ln \left(\mathrm{Z}_{10} / \mathrm{Z}_{0}\right)}
\end{aligned}
$$

where

$$
\begin{aligned}
& Z_{y} \text { - height above the ground, } \\
& Z_{o} \text { - roughness parameter, } \\
& \overrightarrow{\mathbf{v}_{\mathbf{z}}} \text {-mean wind speeds at height } Z_{y} \text {. }
\end{aligned}
$$

When selecting sites, infrastructural facilities such as roads should also be considered. The roughness parameter $Z_{o}$ is the height above the ground level where the wind speed is theoretically zero. It is mainly used to characterize shear. This value is not constant but rather site specific since it varies according to the terrain of the site. Investigation about the variation of the roughness parameter has been done by various researchers and a table providing the roughness parameter lengths for different terrain descriptions is summarized [8]. Surface roughness parameter can be calculated using the simplified equation below $[9,10]$ :

$$
\ln Z_{o}=\frac{V_{10} \ln \left(Z_{y}\right)-V_{y} \ln \left(Z_{10}\right)}{V_{10}-V_{y}}
$$

Power output is calculated by use of the Rayleigh power density function shown by

$$
P_{R}=\frac{3}{\pi} \rho C^{3}\left(\frac{\pi}{4}\right)^{3 / 2}
$$

where $k$ is the shape parameter and $C$ Weibull scale parameter $(\mathrm{m} / \mathrm{s})$, and $\rho$ air density $\left(\mathrm{kg} / \mathrm{m}^{3}\right)$

The value of $\mathrm{k}$ and $C$ can be easily determined by the following equations:

$$
k=\left(\frac{\sigma}{\bar{V}}\right)^{-1.086}
$$

where $\sigma$ is the Weibull distribution variance and $\vec{v}$ is mean wind speed at height $z$,

$$
C=\vec{V}\left(0.568+\frac{0.433}{k}\right)^{-1 / k}
$$

2.1.2. Methods of Extrapolating Weibull Parameters. Weibull phase factor $k$ and scale factor $C$ for given know heights can be extrapolated to other hub heights by using the following formulas [11, 12]:

$$
\begin{aligned}
C_{z} & =C_{10} \times\left(\frac{z}{z_{10}}\right)^{n} \\
k_{z} & =\frac{k_{10}}{1-0.008811 \ln (z / 10)}
\end{aligned}
$$

where

$$
n=0.37-0.088 \ln \left(C_{10}\right)
$$

\section{Results and Discussion}

3.1. Wind Shear Exponent Analysis. Wind speed is intermittent in nature due to several factors such as surface roughness length, topographical features of a place, hour of the day, season of the year, temperature stratification, wind direction, and height above the ground. Due to these uncertainties, it is crucial to factor in wind shear exponent and surface roughness parameter when extrapolating wind speed to higher hub heights for power prediction. Wind shear exponent is a factor that gives the vertical fetching characteristics of wind at a site. From Figure 2, it is evident that heating and cooling processes of air just above the earth's surface during the 24hour cycle influence the wind shear coefficient. As depicted by the figures, in the stations of Ikobe and Nyamecheo, during night cold stable hours, wind shear exponent is $t$ its maximum while during day hot stable hours, wind shear is minimum. But despite the fact that Kisii University is part of this region, shear variation at the station differs from the other two. The variation is not uniform but tends to be low during the night and high during the day. This is exactly the opposite of what is depicted from the other two stations. This implies that the variation of wind shear exponent cannot be assumed just by picking data from one site of a place and assume to represent the whole region. This factor varies from place to place, from one period to another period depending on the nature of the topography of the place and temperature variations of the region under investigation.

It is also to be noted that the values, obtained from the three stations and for the six months that were under study, greatly differ from those tabulated based on studies done in other places with the same conditions and surface nature. This therefore can be interpreted to mean that wind shear exponent is site specific and cannot be subject to other places based on assumptions drawn from other researches done in the area. But despite this fact, other researches which have been done in the same area help us to explain the variation of this factor from another angle of approach.

In his research "Wind Shear, Roughness Classes and Turbine Energy Production," Ragheb M., 2018, classifies these behaviors into two classes: stable and unstable. Under unneutral stability of the atmosphere, displacement of air upwards and downwards leads to expansion and contraction without loss or gain of internal energy. During the night, the ground gets cooler hence making air just above it to sink. This 

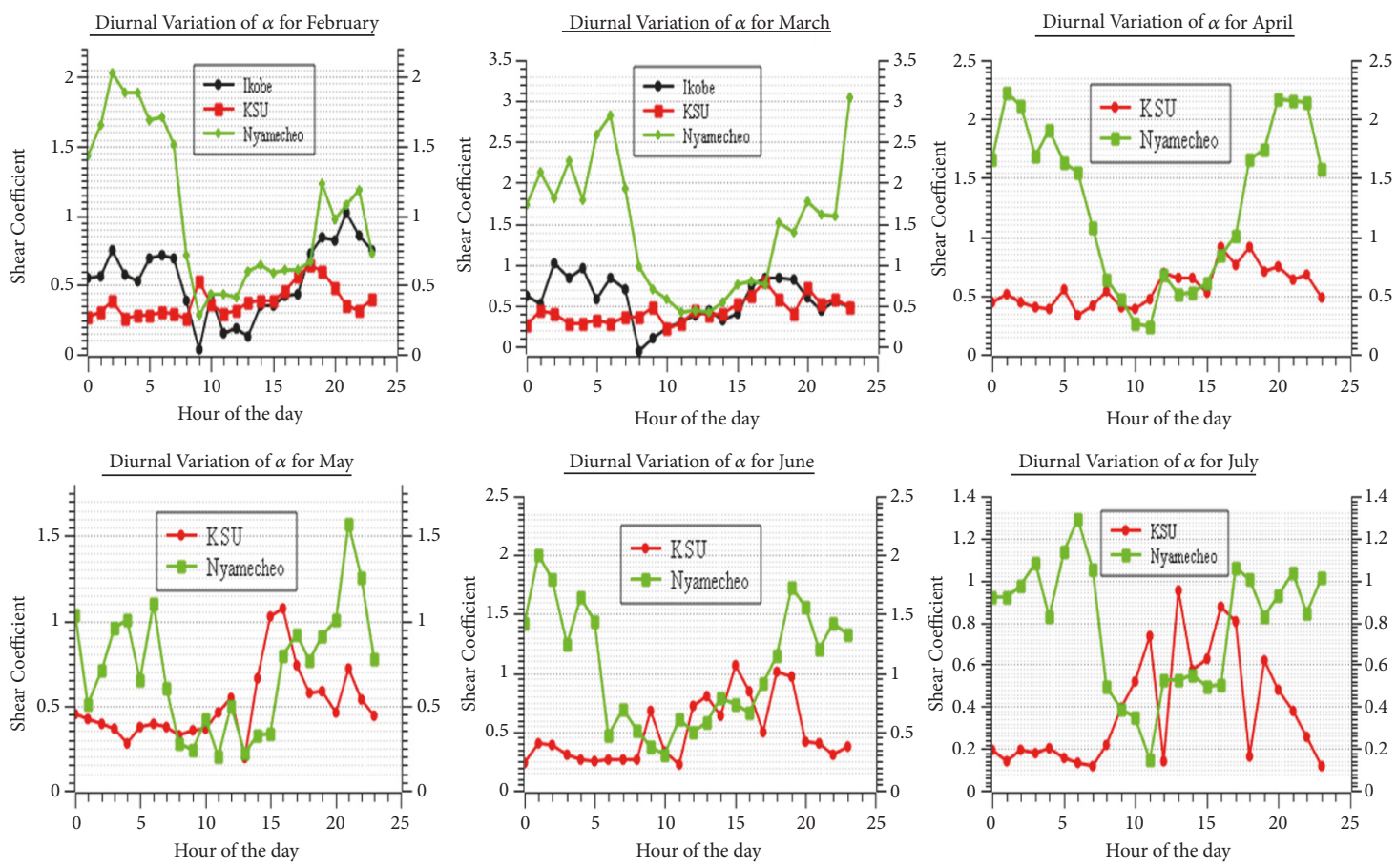

FIGURE 2: Six-month variation of wind shear coefficient for the three stations.

TABLE 1: Averages of calculated wind shear exponents.

\begin{tabular}{lccccccc}
\hline & February & March & April & May & June & July & Average \\
\hline Nyamecheo & 1.0390 & 1.4313 & 0.9186 & 0.5932 & 0.8566 & 0.7204 & 0.9265 \\
Kisii university & 0.3785 & 0.4295 & 0.5368 & 0.4535 & 0.4130 & 0.3022 \\
Ikobe & 0.5389 & 0.5592 & - & - & - & 0.4189 \\
\hline Average & 0.6521 & 0.8067 & 0.7277 & 0.5234 & 0.6348 & 0.5113 & - \\
\hline
\end{tabular}

causes the boundary layer to be shallow and its turbulence suppressed. Due to this condition, the wind speeds are low as shear exponents are at their maximum value. The condition is referred to as stable condition. During the day, the ground gets heated up by solar radiations from the sun causing less dense air to rise. Fluxes of moisture in the atmosphere and at surface combined affect wind profiles near the ground. Wind shear exponent is at its minimum value as winds are at their maximum. The conditions are referred to as unstable conditions and usually are the deepest reaching up to $2 \mathrm{~km}$ high in active convective summer days.

Table 1 gives the average values of wind shear coefficients calculated from the average wind speeds at the three sites which were investigated. From the calculations, the average wind shear exponent for the six-month period ranges between 0.5234 and 0.8067 with an average of 0.6429 and 0.4189-0.9265 for the three stations with Nyamecheo recording the highest and Kisii University the lowest. These values are assumed to give the exact values of wind shear exponent of Kisii region. According to Garrett R. B. [13], wind shear exponent depends on factors like the nature of the terrain of a place, wind speed variation, temperatures among other thermal, and mechanical mixing parameters. This parameter plays an important role in the prediction of wind power of a place as it has a direct impact on wind turbine hub heights hence strongly influencing the cyclic loading of the turbine blades [14].

3.2. Effect of Wind Shear Exponent on Extrapolating Wind Speeds at the Site. In this work, averages of wind speeds from the three stations at heights of $10 \mathrm{~m}$ and $13 \mathrm{~m}$ were used. The measured wind speeds were used to estimate the wind shear exponent of the region. The wind shear exponents were then used to estimate by extrapolation, the wind speeds at higher hub heights of $20 \mathrm{~m}, 30 \mathrm{~m}, 50 \mathrm{~m}$, and $70 \mathrm{~m}$. Table 2 lists the estimated wind speeds. From the values obtained, it is apparent that the estimated wind speeds based on the site determined wind shear factor are beyond doubt different from those estimated using the theoretical wind shear exponent.

\subsection{Effect of Wind Shear Exponent on Wind Power Estimation.}

In this study, effects of wind shear exponent on the region's wind energy yield estimation have been carried out by use of extrapolated wind speeds at higher hub heights by using both the theoretical value of $1 / 7^{\text {th }}$ and on sites determined 
TABLE 2: Extrapolated average wind speeds at different hub heights using site specific wind shear exponent and constant shear exponent (1/7).

\begin{tabular}{|c|c|c|c|c|c|c|c|}
\hline \multirow[t]{2}{*}{ Month } & \multirow[t]{2}{*}{ Hub Height } & \multicolumn{2}{|c|}{$\begin{array}{l}\text { Average wind speed for } \\
\text { Nyamecheo Station }\end{array}$} & \multicolumn{2}{|c|}{$\begin{array}{l}\text { Average wind speed for } \\
\text { KSU Station }\end{array}$} & \multicolumn{2}{|c|}{$\begin{array}{l}\text { Average wind speed for } \\
\text { Ikobe station }\end{array}$} \\
\hline & & $\alpha=0.146$ & $\alpha=0.92$ & $\alpha=0.146$ & $\alpha=0.41$ & $\alpha=0.146$ & $\alpha=0.54$ \\
\hline \multirow{4}{*}{ FEBRUARY } & 20 & 1.64 & 2.56 & 3.05 & 3.67 & 2.09 & 2.73 \\
\hline & 30 & 1.74 & 3.53 & 3.24 & 4.33 & 2.22 & 3.38 \\
\hline & 50 & 1.87 & 5.28 & 3.49 & 5.34 & 2.39 & 4.43 \\
\hline & 70 & 1.97 & 6.88 & 3.67 & 6.13 & 2.47 & 5.30 \\
\hline \multirow{4}{*}{ MARCH } & 20 & 1.11 & 2.00 & 2.52 & 3.03 & 1.59 & 2.06 \\
\hline & 30 & 1.17 & 3.00 & 2.68 & 3.58 & 1.69 & 2.55 \\
\hline & 50 & 1.26 & 5.00 & 2.88 & 4.41 & 1.82 & 3.33 \\
\hline & 70 & 1.33 & 7.00 & 3.03 & 5.06 & 1.91 & 3.96 \\
\hline \multirow{4}{*}{ APRIL } & 20 & 1.12 & 1.92 & 2.21 & 2.66 & - & - \\
\hline & 30 & 1.18 & 2.80 & 2.35 & 3.14 & - & - \\
\hline & 50 & 1.27 & 4.51 & 2.53 & 3.87 & - & - \\
\hline & 70 & 1.34 & 6.16 & 2.66 & 4.44 & - & - \\
\hline \multirow{4}{*}{ MAY } & 20 & 1.29 & 2.22 & 2.90 & 3.48 & & - \\
\hline & 30 & 1.37 & 3.23 & 3.08 & 4.11 & - & - \\
\hline & 50 & 1.47 & 5.20 & 3.31 & 5.07 & - & - \\
\hline & 70 & 1.55 & 7.11 & 3.48 & 5.82 & - & - \\
\hline \multirow{4}{*}{ JUNE } & 20 & 1.12 & 1.92 & 2.56 & 3.07 & - & - \\
\hline & 30 & 1.18 & 2.80 & 2.71 & 3.62 & - & - \\
\hline & 50 & 1.27 & 4.50 & 2.92 & 4.47 & - & - \\
\hline & 70 & 1.34 & 6.16 & 3.07 & 5.13 & - & - \\
\hline \multirow{4}{*}{ JULY } & 20 & 1.65 & 2.84 & 3.65 & 4.38 & - & - \\
\hline & 30 & 1.75 & 4.14 & 3.87 & 5.18 & - & - \\
\hline & 50 & 1.88 & 6.66 & 4.17 & 6.38 & - & - \\
\hline & 70 & 1.99 & 9.10 & 4.38 & 7.33 & - & - \\
\hline
\end{tabular}

wind shear exponent. MATLAB software has been used in the estimation of wind speeds and wind power in both scenarios. From Figures 3, 4, and 5, it is clear that if a 10m wind speed is extrapolated at the site with the theoretical wind shear exponent of 0.146 , then the energy output at the region would be seriously underestimated. Figures 3, 4, and 5 show power difference when using the two values for Nyamecheo, Kisii University, and Ikobe stations, respectively, for the six-month period. It is evident from all the stations that topography plays a critical role in determining energy discrepancy at any site. According to Saif et al, 2015, these discrepancies must be adopted when performing prefeasibility studies of wind energy production assessment.

On average, air density of Kisii region based on this research has been calculated and found to be equal to $1.1942 \mathrm{~kg} / \mathrm{m}^{2}$. Wind shear exponent and roughness parameters depended on wind speed and air density. Just like wind speeds, air density also varies with height. The results show that air density decreases with height due to the vertical drop of air pressure in higher altitudes.

3.4. The Roughness Parameter Length. Accurate prediction of wind speed to different hub heights is vital for any wind energy investor. For one to invest in wind energy, availability of adequate wind profiles is necessary to enable making an informed choice on whether to invest on or not and on the selection of the best machine that can match the wind profiles of the given site. In profiling, surface roughness parameter is mandatory since it acts as the reference point for extrapolation purposes. In this research, the average roughness parameter for two months has been calculated and recorded in Table 3. How this parameter varies from hour to hour is presented in Figure 6. The overall mean $Z_{o}$ for Nyamecheo, Kisii University, and Ikobe stations has been calculated and found to be $3.7544 \mathrm{~m}, 1.3248 \mathrm{~m}$, and $1.9616 \mathrm{~m}$, respectively. This value is not constant but rather site specific since it varies according to the terrain of the site.

Investigation about the variation of the roughness parameter has been done by various researchers and a table providing the roughness parameter lengths for different terrain descriptions summarized [8]. Kisii region is hilly and receives rain all year round, something which makes the place bushy and with many trees. Based on this, the region can be categorized under terrain description of many hills, hedges, and few buildings with a roughness parameter of 0.25 . But when this value is compared with practical values obtained at the site, there is a huge difference. This gap in the findings can be argued based on many contributing unique factors at 


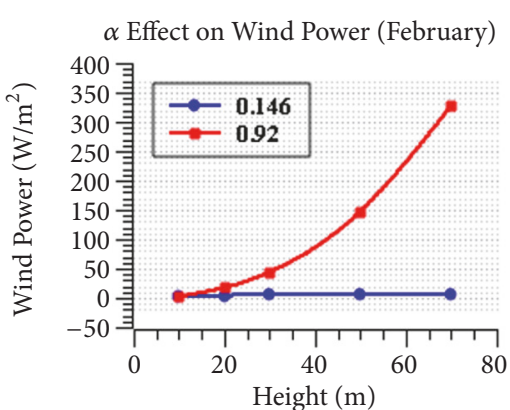

$\alpha$ Effect on Wind Power (May)

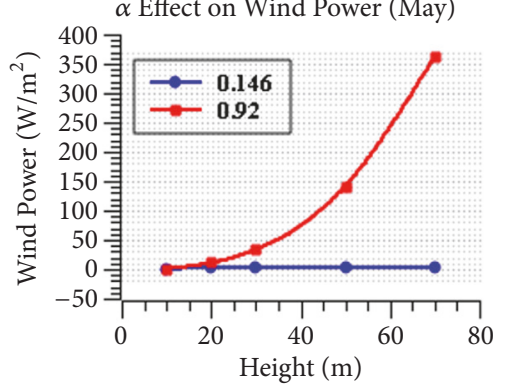

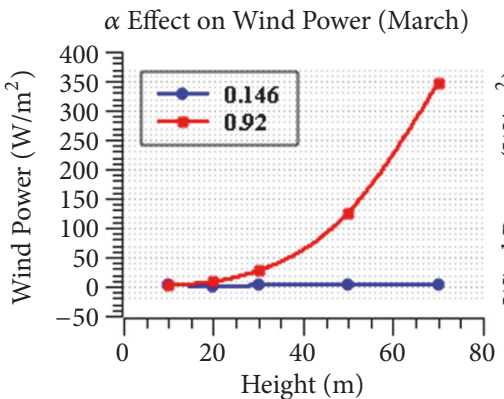

$\alpha$ Effect on Wind Power (June)

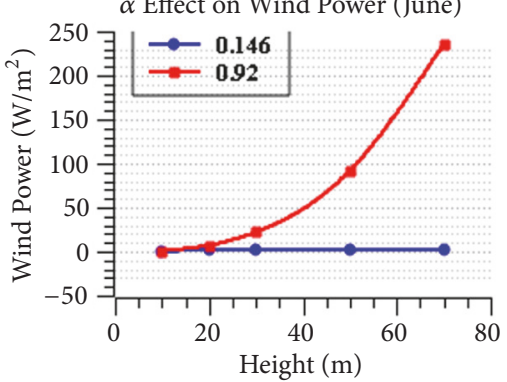

$\alpha$ Effect on Wind Power (April)

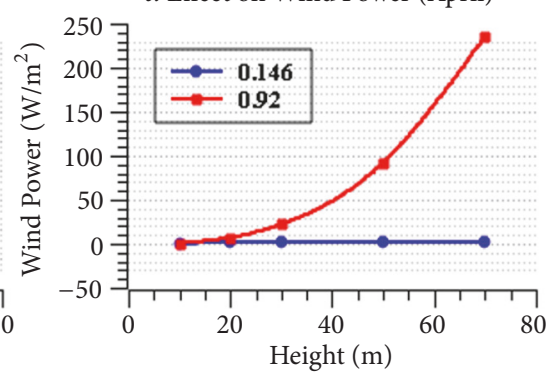

$\alpha$ Effect on Wind Power (July)

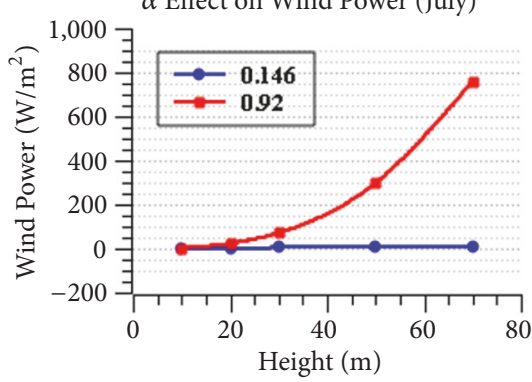

FIGURE 3: Effect of wind shear exponent on wind energy yield for Nyamecheo station.

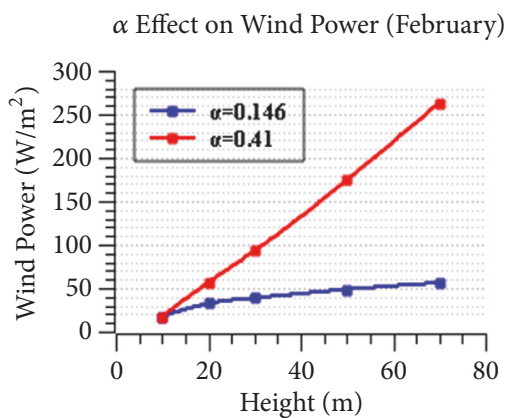

$\alpha$ Effect on Wind Power (March)

$\alpha$ Effect on Wind Power (April)
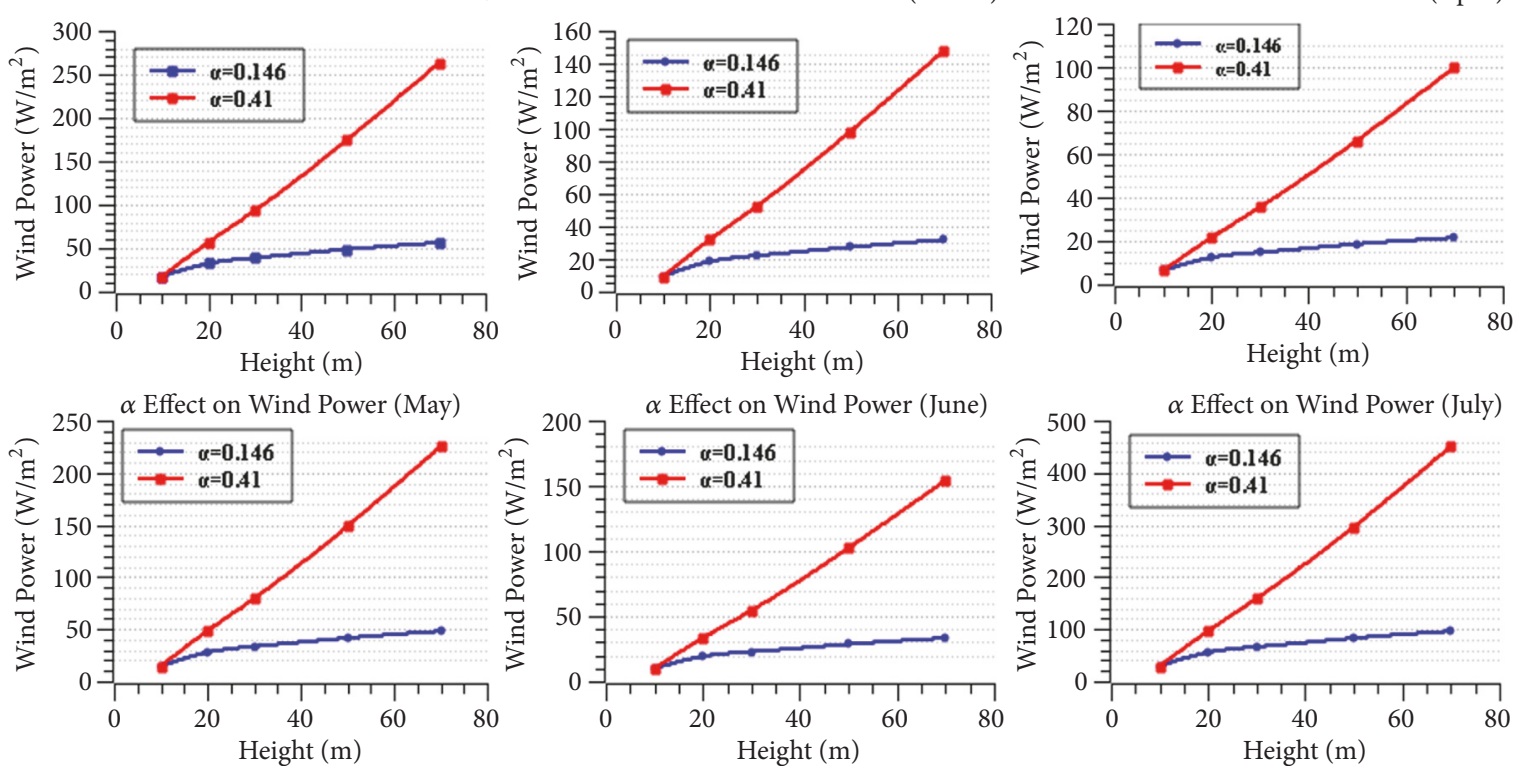

FIGURE 4: Effect of wind shear exponent on wind energy yield for Kisii University station.

TABLE 3: Average roughness parameter length.

\begin{tabular}{|c|c|c|c|c|c|c|c|}
\hline & February & March & April & May & June & July & Average \\
\hline Nyamecheo & 3.6980 & 4.8608 & 4.5549 & 2.5305 & 3.8555 & 3.0266 & 3.7544 \\
\hline Kisii university & 0.7721 & 1.1463 & 1.9226 & 1.5376 & 1.4991 & 1.0711 & 1.3248 \\
\hline Ikobe & 1.9314 & 1.9917 & - & - & - & - & 1.9616 \\
\hline Average & 2.1338 & 2.6663 & 3.2388 & 2.0341 & 2.6773 & 2.0489 & 2.3469 \\
\hline
\end{tabular}



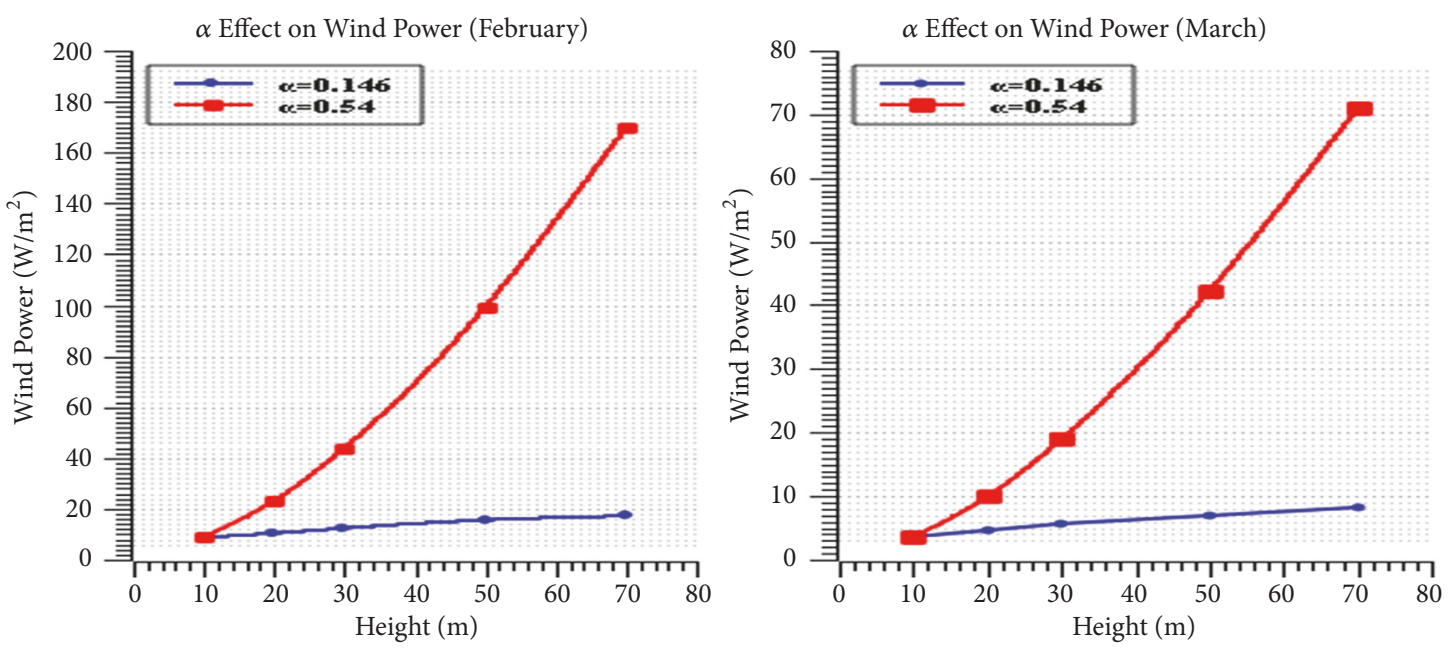

FIGURE 5: Effect of wind shear exponent on wind energy yield for Ikobe station.
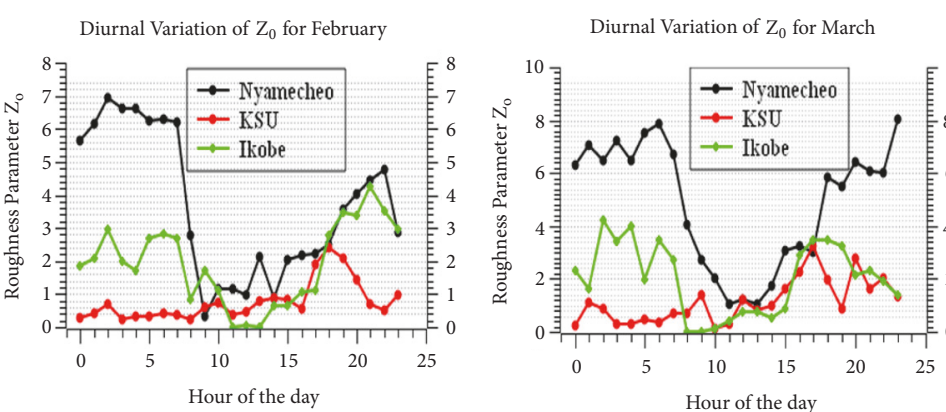

Diurnal Variation of $\mathrm{Z}_{0}$ for June
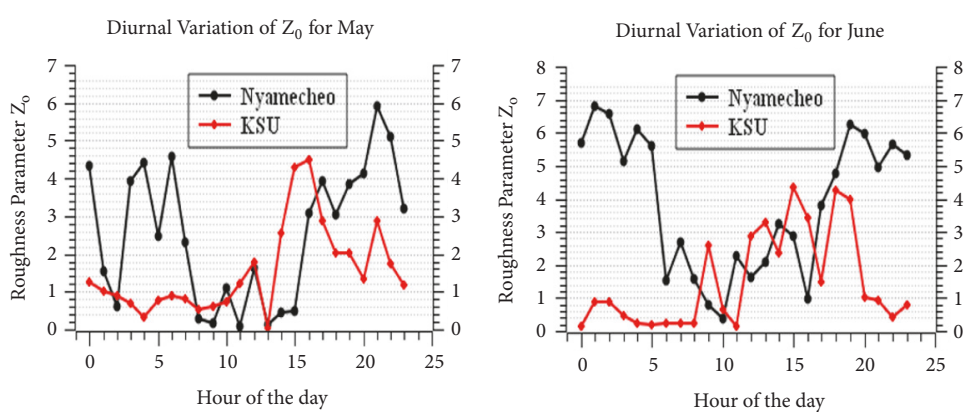

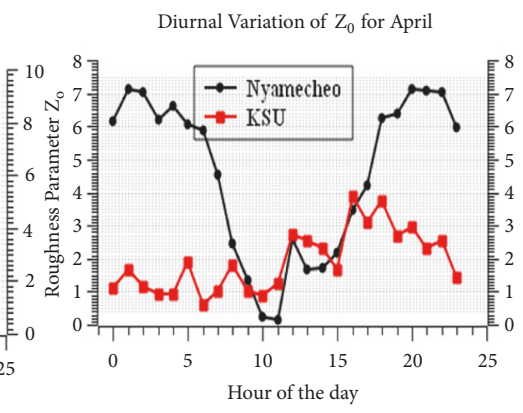

Diurnal Variation of $\mathrm{Z}_{0}$ for July

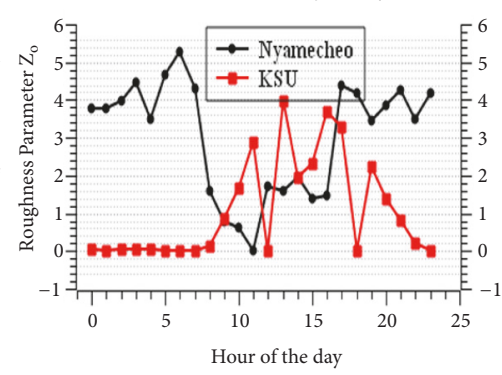

FIGURE 6: Diurnal variation of surface roughness parameter $\left(Z_{o}\right)$ at the selected sites for the six months.

the site. Kisii region is highly populated, something which makes the place have so many buildings congested at the site. The soils of the site are fertile and famers practice small scale crop farming all year round and trees at site grow tall due to enough rain and good soils. Also the place is invested with small hills which are very close. These factors when added up together give a good reason as to why the values obtained practically contradict those obtained by the other researchers on variation of this factor based on terrains. This implies that, as much as there is already established theoretical roughness parameter values to help categorize regions when assessing wind power potentials, practical research of the roughness parameter needs to be done before setting up a wind firm.
As it can be seen from Figure 6, variation of $Z_{0}$ for all stations showed a pattern where maximum values were obtained during the night stable hours with minimum values obtained during day hours like in wind shear distribution. This pattern can be associated with the diurnal heating and cooling of the hearth's surface causing pressure imbalance. Surface roughness parameter of a locale is dependent on surface cover characteristics. In determining surface roughness parameter, the survey of the terrain is necessary.

According to Garratt, 1992, surface roughness variation depends on the geometry, spacing, and arrangement of roughness parameter on the earth's surface. Variation characteristics of this parameter at a site have a major influence 

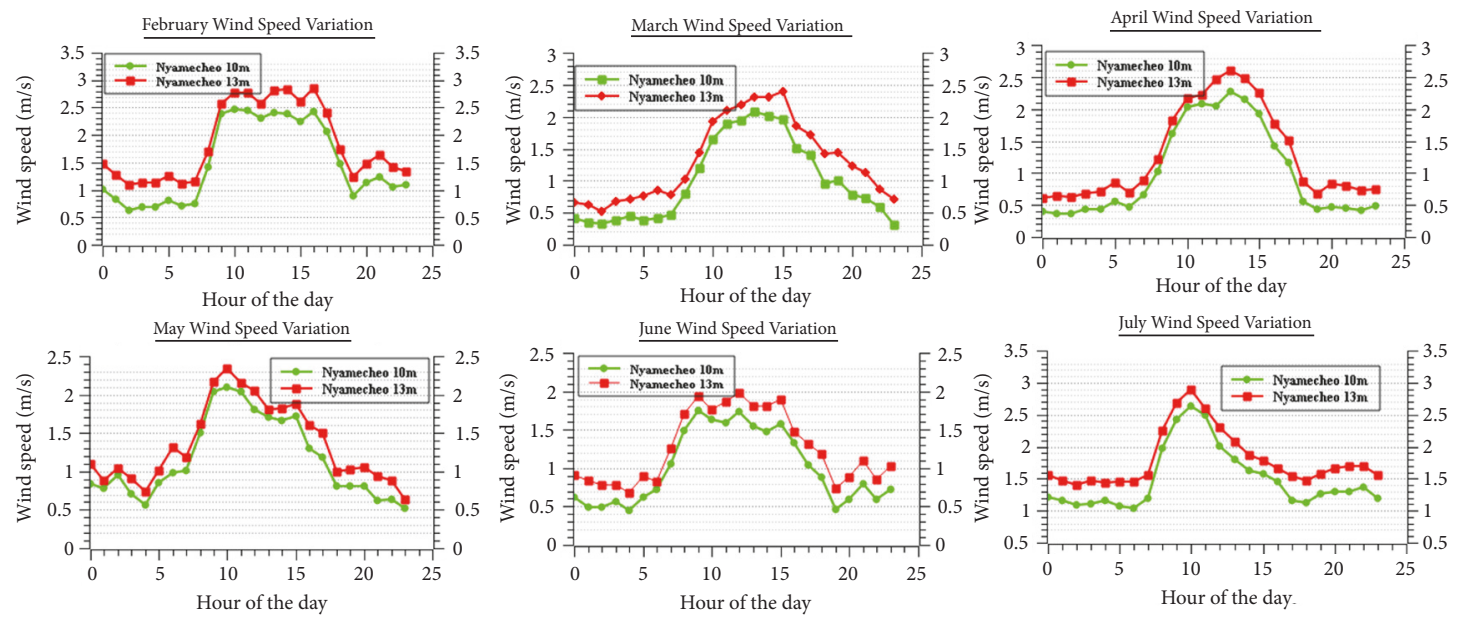

FIGURE 7: Nyamecheo site diurnal variation of wind speeds for months of February to July.
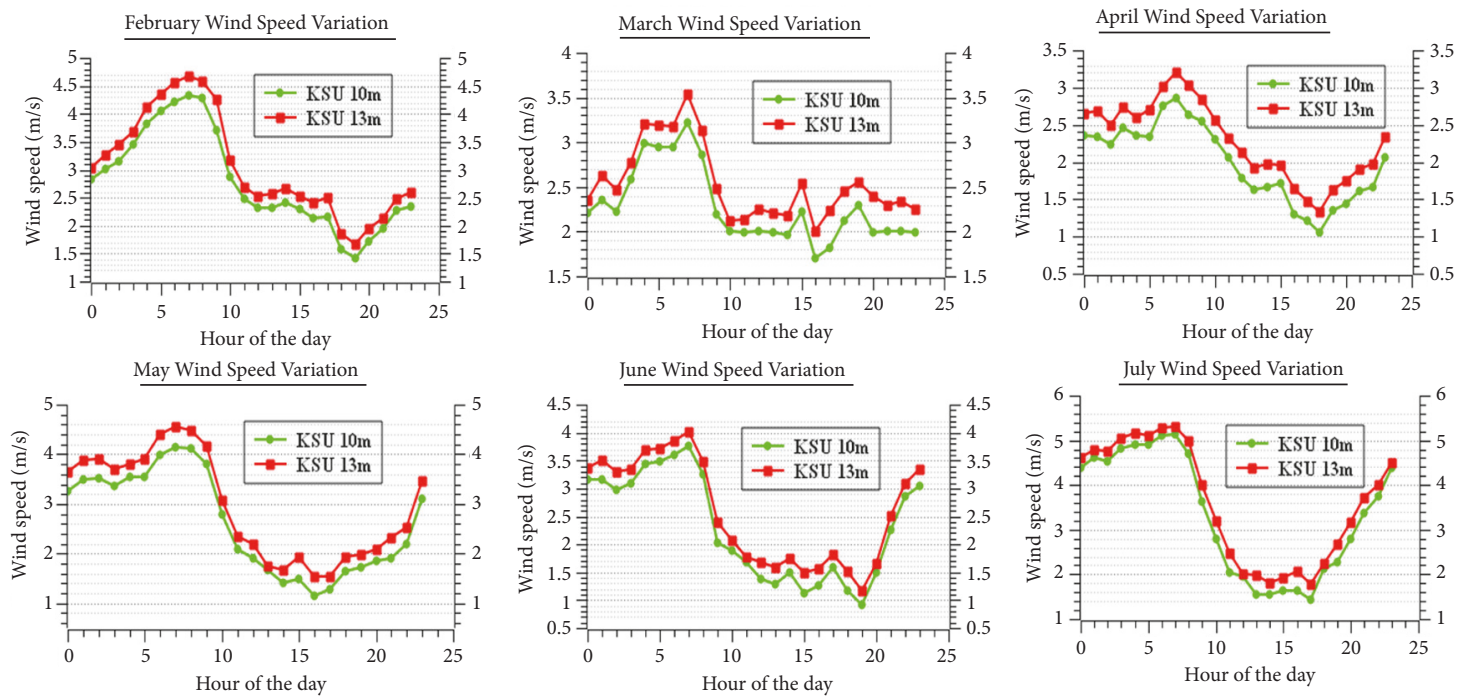

FIGURE 8: Kisii University (KSU) site diurnal variation of wind speeds for months of February to July.

on wind regime at the surface layer. Kisii region is invested with complex topographical features like hills and bushes something which causes a considerable variation of wind speeds across the region. The vertical distribution of wind speeds as indicated in Figures 7, 8, and 9 is a function of surface roughness parameter and wind shear exponent based on atmospheric stability at the site.

Figures 7, 8, and 9 show hourly variation of wind speeds at the sites for the six months. From the figures, it is evident that wind speeds at the site have an inverse variation with surface roughness parameter. During night stable hours, when the wind speed values at both heights of $10 \mathrm{~m}$ and $13 \mathrm{~m}$ are at their minimum values, roughness parameters values are at their peak. During day stable hours, when wind speed values are at their maximum, surface roughness parameter values are at their minimum. This variation is vital for predicting long term variation of one of these parameters at the site given long term data of the other parameter.
The information on variation of wind speed with surface roughness parameter is of critical importance especially when identifying preferred shapes, orientations, and optimizing the layout of wind turbine within a wind farm. The graphs demonstrate a smooth and predictable diurnal wind speed distribution patterns with high wind speeds prevailing from approximately 1100 hours to around 1600 hours for stations of Ikobe and Nyamecheo with Kisii showing a different pattern with prevailing winds appearing approximately between the 0300hrs and $0800 \mathrm{hrs}$. This implies that, for the stations of Ikobe and Nyamecheo, the wind speed is high during the mid-day approaching evenings when the temperature is high. While on the other hand, wind speed is high after midnight approaching down for the Kisii station when the temperatures are low and are in reducing trend. Kisii at the prevailing wind recorded high wind speeds as compared to Ikobe and Nyamecheo. These variations are directly linked to differential heating up of the surface depending on the nature 

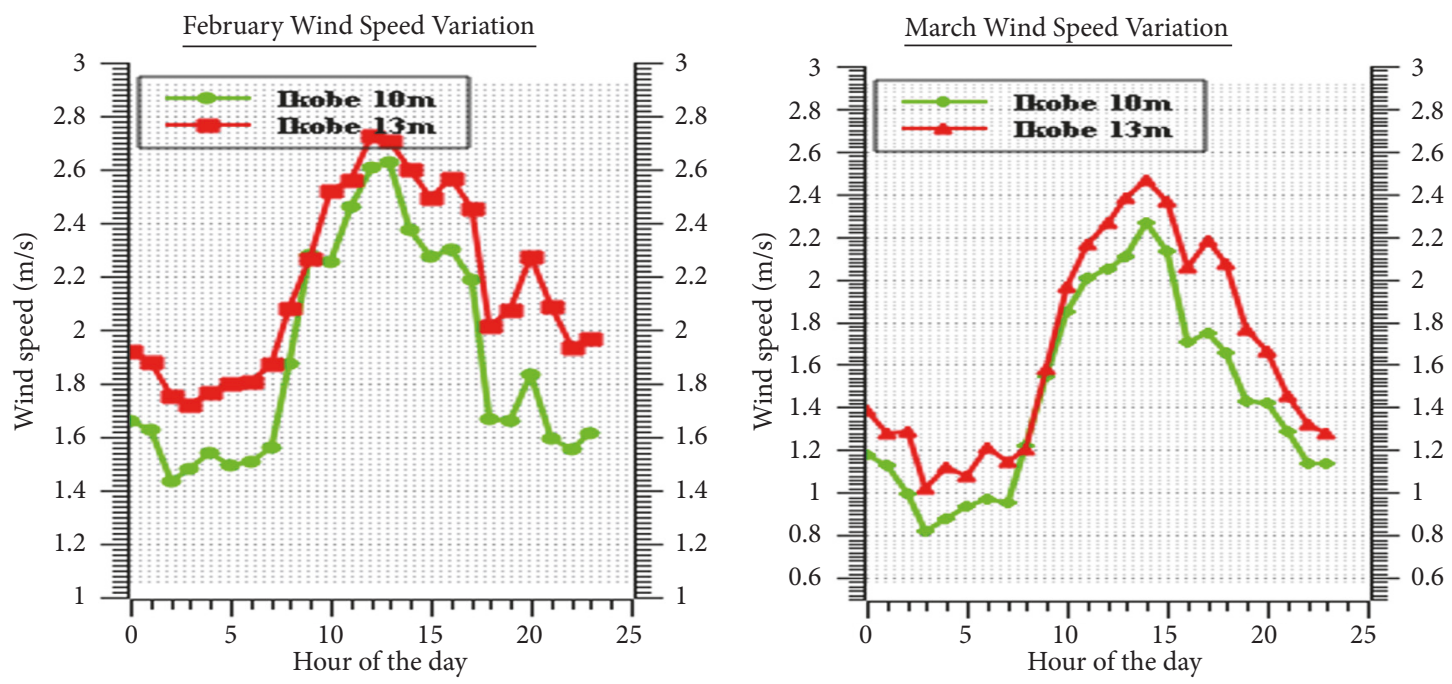

FIGURE 9: Ikobe site diurnal variation of wind speeds for months of February and March.

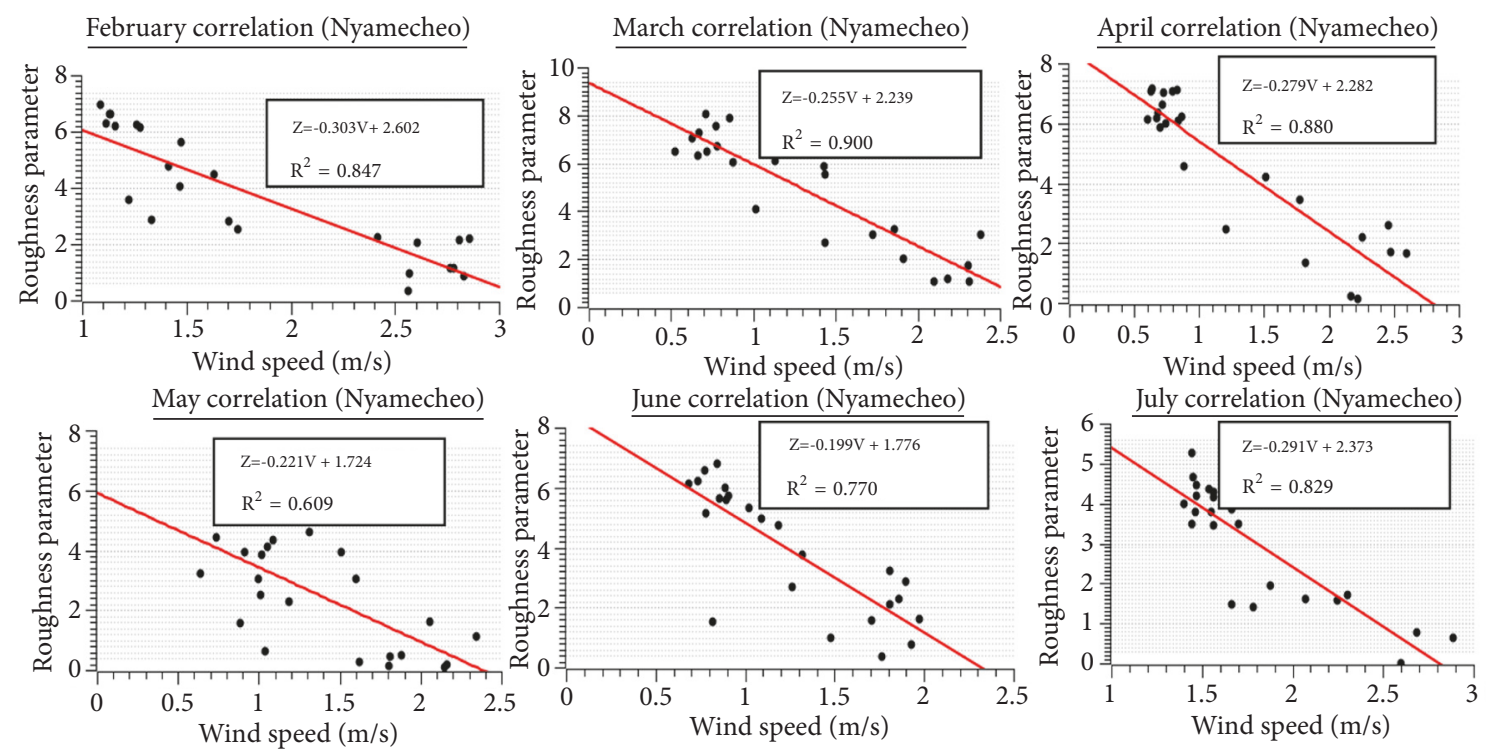

FIGURE 10: Correlation of wind speeds and roughness parameter for Nyamecheo station.

of the terrain hence surface roughness parameter. Therefore for effective installation of wind power station at any site, practical information on variation of wind power and surface roughness is mandatory.

\subsection{Correlation between Wind Speed and Roughness Parame-} ter. Correlation between wind speed and surface roughness parameter has also been done. As is depicted in Figures 10, 11 , and 12, wind speed has, in average, a strong negative correlation $(\approx-0.80)$ with roughness parameter $Z_{o}$. Using the measure, correlate, and predict method, the wind speeds and surface roughness parameter of the stations have been predicted and equations of prediction given. The shearvelocity trend analysis has been presented in the figures and models developed as per station which can be used to explain the variability of one the variables given the long term data of the other variable. The shear-velocity trend of Nyamecheo station gives a very strong coefficient of correlation of $\approx$ -0.9 which implies that the model is very reliable for future forecasts of either of the variables given data of the other. Kisii university on the other hand gives a strong coefficient of correlation of $\approx-0.75$ which implies that the model can be relied on for future forecasts though with lesser reliability when compared to that of Nyamecheo station. Ikobe station has a strong correlation coefficient of $\approx-0.71$.

Figure 13 shows hourly variation of surface roughness parameter and wind speeds at the sites for the six months under study. From the figures, it is clear that roughness parameter and wind speeds at the site have an inverse variation. It is demonstrated from stations of Nyamecheo and 

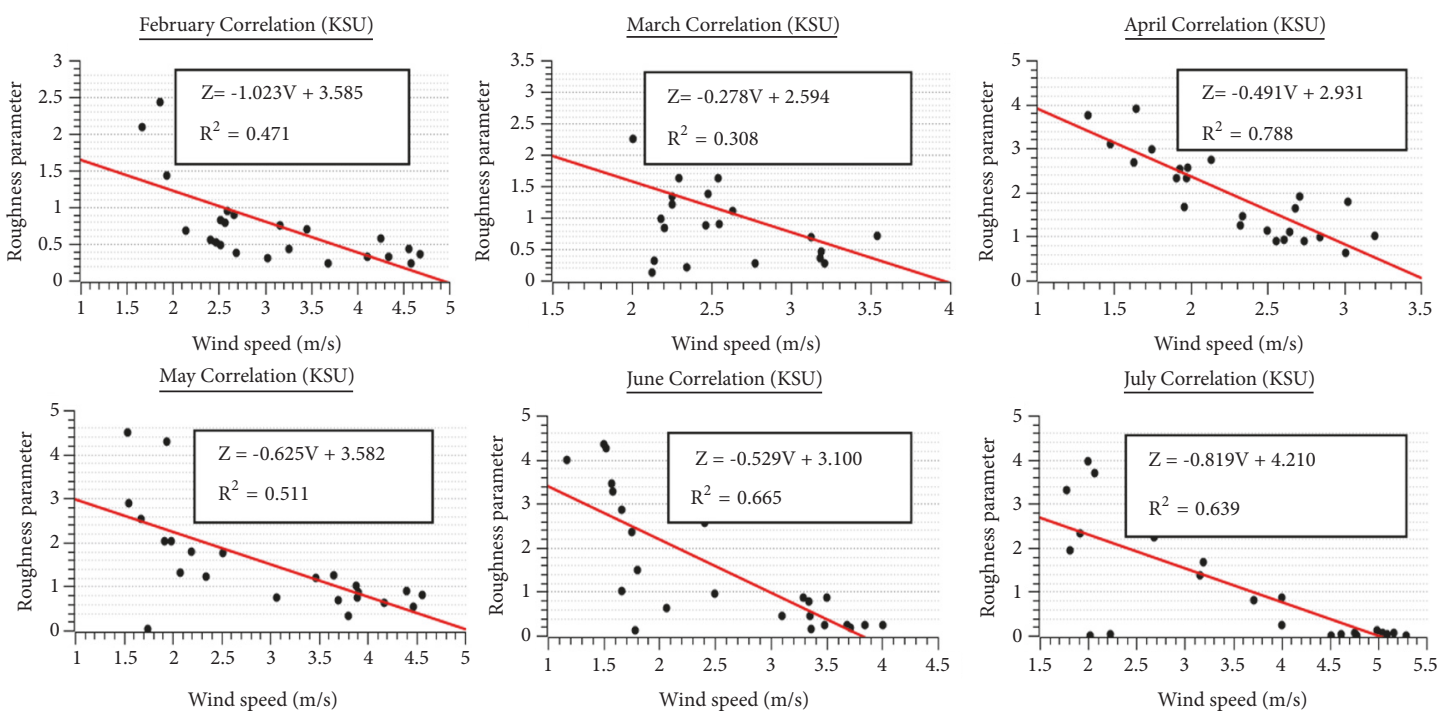

FIGURE 11: Correlation of wind speeds and roughness parameter for Kisii University station.
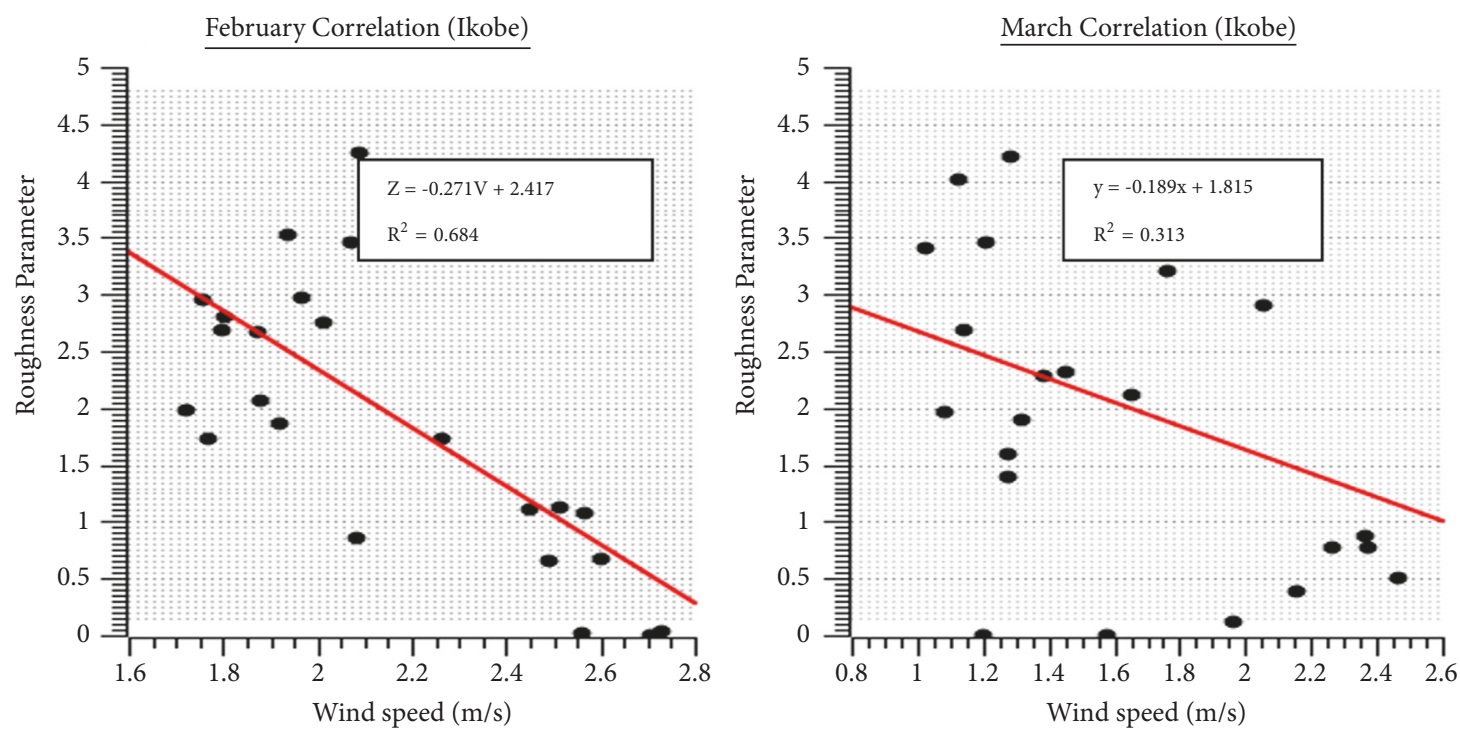

FIGURE 12: Correlation of wind speeds and roughness parameter for Ikobe.

Ikobe that, during night stable hours, when the wind speed values at the heights of $10 \mathrm{~m}$ are at their minimum values, roughness parameters values are at their peak. During day stable hours, when wind speed values are at their maximum, surface roughness parameter values are at their minimum. Conversely, Kisii University, despite of lying within the same region, demonstrates the opposite behavior. In this site, the value of roughness parameter increases during the day and decreases as the atmosphere begins to separate into layers during the nocturnal hours. This can be associated with prevalence of surface heating and the mixing effects that the sites have on the atmosphere which differs depending on site's resistance to the flow of air over the terrain
Table 4 gives a summary record of statistically computed estimations of normal wind speed, variance, standard deviation, wind power, wind direction, shape factor, and scale factor parameters of the Kisii locale for the period of 6 months that were under study. As it can be indicated from the table, the most astounding average wind speed is $3.16 \mathrm{~m} / \mathrm{s}$ and the least $1.21 \mathrm{~m} / \mathrm{s}$ with standard deviations of $1.72 \mathrm{~m} / \mathrm{s}$ and $1.20 \mathrm{~m} / \mathrm{s}$, respectively. Likewise from the table, it can be noticed that the estimations of shape factor range from 1.01 to 1.71 while the scale factor extends between $3.16 \mathrm{~m} / \mathrm{s}$ and $1.21 \mathrm{~m} / \mathrm{s}$. The shape factor $\mathrm{k}$ indicates how peaked the wind conveyance is at the sites. From the estimations of values of $\mathrm{k}$ recorded in Table 4, it can be stated that wind speed is highly peaked in Kisii University and Ikobe but lowly peaked in Nyamecheo. Wind 

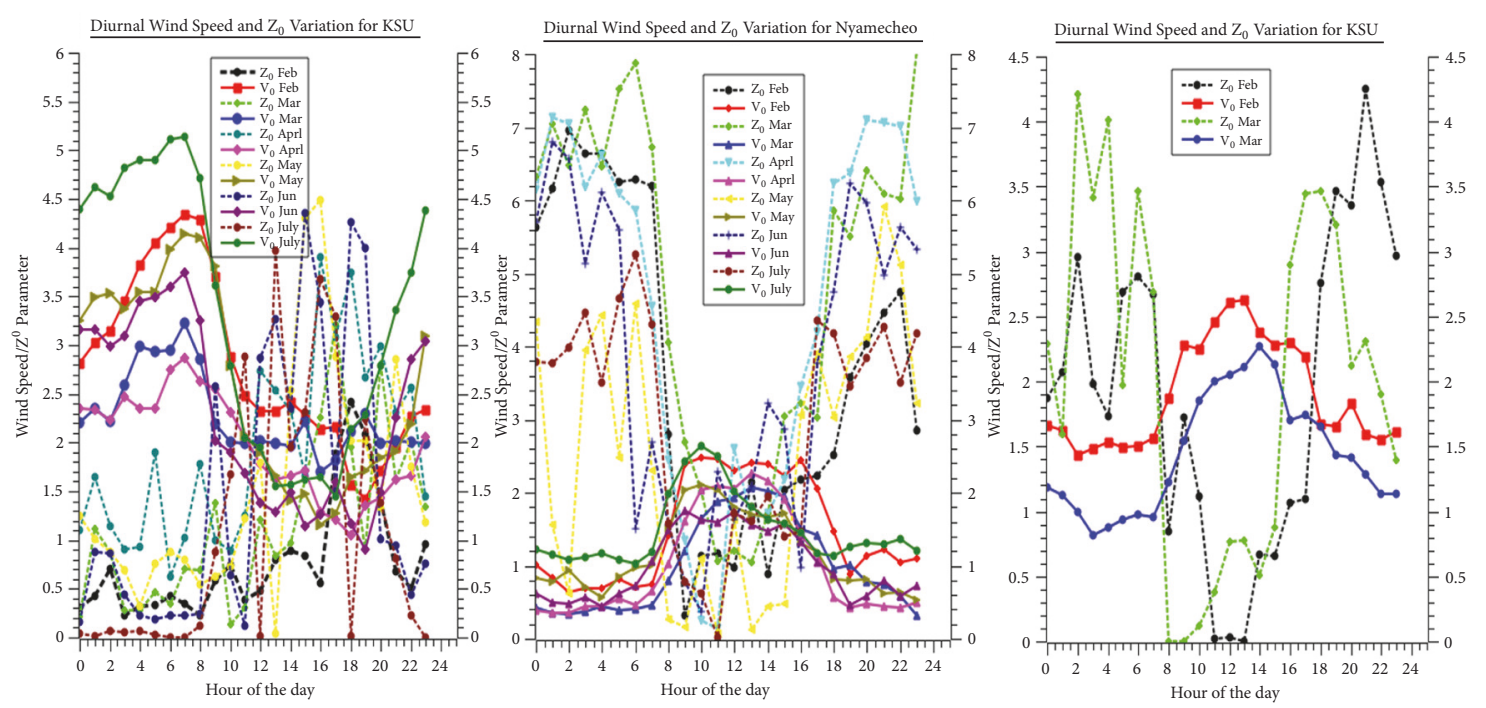

FIGURE 13: Diurnal variation of surface roughness parameter and wind speeds at the sites.

TABLE 4: Statistical summary of wind characteristics at the sites.

\begin{tabular}{|c|c|c|c|c|c|c|c|c|c|c|}
\hline \multicolumn{11}{|c|}{ NYAMECHEO STATIONS } \\
\hline Station & Labels & $\begin{array}{l}\text { Height } \\
(\mathrm{m})\end{array}$ & $\begin{array}{l}\text { Peak V } \\
\left(\mathrm{ms}^{-1}\right)\end{array}$ & $\begin{array}{c}\text { Mean V } \\
\left(\mathrm{ms}^{-1}\right)\end{array}$ & $\mathrm{K}$ & $\mathrm{C}(\mathrm{m})$ & $\begin{array}{l}\text { Power } \\
\left(\mathrm{wm}^{-2}\right)\end{array}$ & Variance & St.dev & Direction \\
\hline 1 & A & 10 & 3.15 & 1.21 & 1.01 & 1.21 & 1.132 & 1.43 & 1.20 & $\mathrm{E}$ \\
\hline 2 & B & 13 & 3.48 & 1.50 & 1.21 & 1.60 & 2.619 & 1.60 & 1.26 & $\mathrm{E}$ \\
\hline \multicolumn{11}{|c|}{ KISII UNIVERSITY STATIONS } \\
\hline 3 & $\mathrm{C}$ & 10 & 4.83 & 2.54 & 1.55 & 2.83 & 14.494 & 2.89 & 1.70 & $\mathrm{E}$ \\
\hline 4 & $\mathrm{D}$ & 13 & 5.13 & 2.82 & 1.71 & 3.16 & 20.179 & 2.97 & 1.72 & $\mathrm{E}$ \\
\hline \multicolumn{11}{|c|}{ IKOBE STATIONS } \\
\hline 5 & $\mathrm{E}$ & 10 & 3.75 & 1.64 & 1.62 & 1.83 & 3.919 & 1.10 & 1.05 & $\mathrm{E}$ \\
\hline 6 & F & 13 & 4.16 & 1.94 & 1.65 & 2.17 & 6.534 & 1.49 & 1.22 & $\mathrm{E}$ \\
\hline
\end{tabular}

direction at both sites appeared to be constrained towards NE and SE with East dominating implying East winds. The wind power at the sites is low as can be indicated in Table 4, but if wind turbines are set at higher hub heights, the region can give wind power for small scale applications. The region is classified as a poor location based on the WPD at the heights of $10 \mathrm{~m}$ and $13 \mathrm{~m}$.

\section{Conclusion}

The main aim of this research was to establish enhancedquality surface roughness parameter and wind shear exponent values and their diurnal and monthly variation for increased accuracy of local and regional wind resource characterization in Kisii region. From results, it has been demonstrated that the drastically vertical variation of wind profiles is dependent on time of the day, topography, and season. It is revealed that, $\alpha$ decreases as the sun rises and increases as the atmosphere begins to separate into layers during the nocturnal hours. Also it can be concluded that the value of $\alpha$ determined from the on-site measurement of wind profiles is best in characterizing wind speeds at higher hub heights as compared to the use of the theoretical value of $1 / 7^{\text {th }}$. Based on this discrepancy, the research suggest that for more accurate assessment of wind resources, surface roughness parameter and wind shear exponent should be determined from field measurements.

It has been demonstrated that a decrease in surface roughness parameter causes increasing trends in wind speeds. It has also been noted that the trends in surface roughness and shear exponent are not uniform. They differ from station to station an implication that no single values can be attached to represent the region but should be determined from time to time for accuracy in wind power prediction at higher hub heights. Though tentatively, experimentally generated averaged value representing the site can be used instead of the assumed theoretical value in each case. From correlational analysis done between surface roughness parameter and surface wind speeds, it is revealed that wind speed and surface roughness parameter are inversely proportional and models can be developed for forecasting the variation of one variable at a time given the other and the reference height. It has been 
demonstrated that the use of wind shear exponent and surface roughness parameter length enhanced by field measurements will be of great benefit to a wind firm sustainability modeling and turbine micro siting at region since it explains the expected behavior of wind.

\section{Data Availability}

The data used to support and conclude the findings of this research are available from the corresponding authors upon request. Meanwhile vital information has been included within supplementary information file.

\section{Disclosure}

This paper has been presented at the Kibabii $3^{\text {rd }}$ Interdisciplinary International Scientific Conference, 2018, but not published.

\section{Conflicts of Interest}

We as authors declare that there is no whatsoever any conflict of interest in this paper.

\section{Acknowledgments}

As authors, we thank the National Research Fund (NRF) for the financial support that they accorded the research. We also thank NACOST for the academic permit provided that enabled this research to be carried out at the region.

\section{Supplementary Materials}

Table 1 in the supplementary data document represents organized data from the raw data obtained from the experiments set at the mentioned sites for the month of February. It is the data that was used to plot graphs that shows how roughness parameter $\left(\mathrm{Z}_{\mathrm{o}}\right)$ varies at the site and later in concluding the findings. Table 2 shows data that was used to draw conclusion on the variation of roughness parameter for the month of March at the site. Table 3 on the supplementary data shows the calculated power based on the theoretical wind shear exponent of $1 / 7^{\text {th }}$ and the on-site calculated value. In Table 3 , the first and second row correspond to wind power calculated from the $1 / 7^{\text {th }}$ theoretical value and on-site calculated value for the month of February, respectively, while rows 3 and 4 of the table represent wind power calculated from the $1 / 7^{\text {th }}$ theoretical value and on-site calculated value for the month of March, respectively. Raw data has not been included in the supplementary data but can be obtained from authors upon request. (Supplementary Materials)

\section{References}

[1] C. W. Kent, K. Lee, H. C. Ward et al., "Aerodynamic roughness variation with vegetation: analysis in a suburban neighbourhood and a city park," Urban Ecosystems, vol. 21, no. 2, pp. 227243, 2018.

[2] M. E. Okorie, F. Inambao, and Z. Chiguvare, "Evaluation of wind shear coefficients, surface roughness and energy yields over inland locations in Namibia," Procedia Manufacturing, vol. 7, pp. 630-638, 2017.

[3] O. C. Saoke, Analysis of wind speeds based on the Weibull model and data correlation for wind pattern description for a selected site in Juja, Kenya. [Master's Thesis], University of JKUAT Kenya, Juja, Kenya, 2011.

[4] A. Bagavathsingh, C. V. Srinivas, P. S. Maran, R. Baskaran, B. Venkatraman, and P. S. Maran, "Wind direction dependent vertical wind shear and surface roughness parameter in two different coastal environments," in Proceedings of The International Conference on Radiological Safety in Workplace, Nuclear Facilities And Environment, vol. 9, Kalpakkam, India, 2016.

[5] S. Emeis, K. Schäfer, and C. Münkel, "Surface-based remote sensing of the mixing-layer height-a review," Meteorologische Zeitschrift, vol. 17, no. 5, pp. 621-630, 2008.

[6] Z. Şen, A. Altunkaynak, and T. Erdik, "Wind velocity vertical extrapolation by extended power law," Advances in Meteorology, vol. 2012, Article ID 178623, 6 pages, 2012.

[7] M. Ragheb, "Wind shear, roughness classes and turbine energy production," 2018.

[8] J. F. Manwell, J. G. McGowan, and A. L. Rogers, Wind Energy Explained, Theory, Design and Application, UK, Theory, Design and Application, Wiley, 2002.

[9] A. N. Celik, "A statistical analysis of wind power density based on the Weibull and Rayleigh models at the southern region of Turkey," Journal of Renewable Energy, vol. 29, no. 4, pp. 593-604, 2004.

[10] L. Bereket, Numerical Simulation of Wind Distribution for Resource Assessment in Southern Eritrea, East Africa, Department of Mechanical Engineering Santa Clara University, 2002.

[11] C. G. Justus, W. R. Hargraves, A. Mikhail, and D. Graber, "Methods for estimating wind speed frequency distributions," Journal of Applied Meteorology and Climatology, vol. 17, no. 3, pp. 350-353, 1978.

[12] B. K. Sexena and K. V. S. Rao, "Comparison of Weibull parameters computation methods and analytical estimation of wind turbine capacity factor using polynomial power curve model: case study of a wind farm," Renewables: Wind, Water, and Solar, vol. 2, no. 1, pp. 1-11, 2015.

[13] R. B. Garrett, Investigations of Surface Roughness Length Modification in Black Rock City, NV [Master, Thesis], San Francisco State University, 2015.

[14] C. Hsieh and C. Dai, "The analysis of offshore islands wind characteristics in Taiwan by Hilbert-Huang transform," Journal of Wind Engineering \& Industrial Aerodynamics, vol. 107-108, pp. 160-168, 2012. 

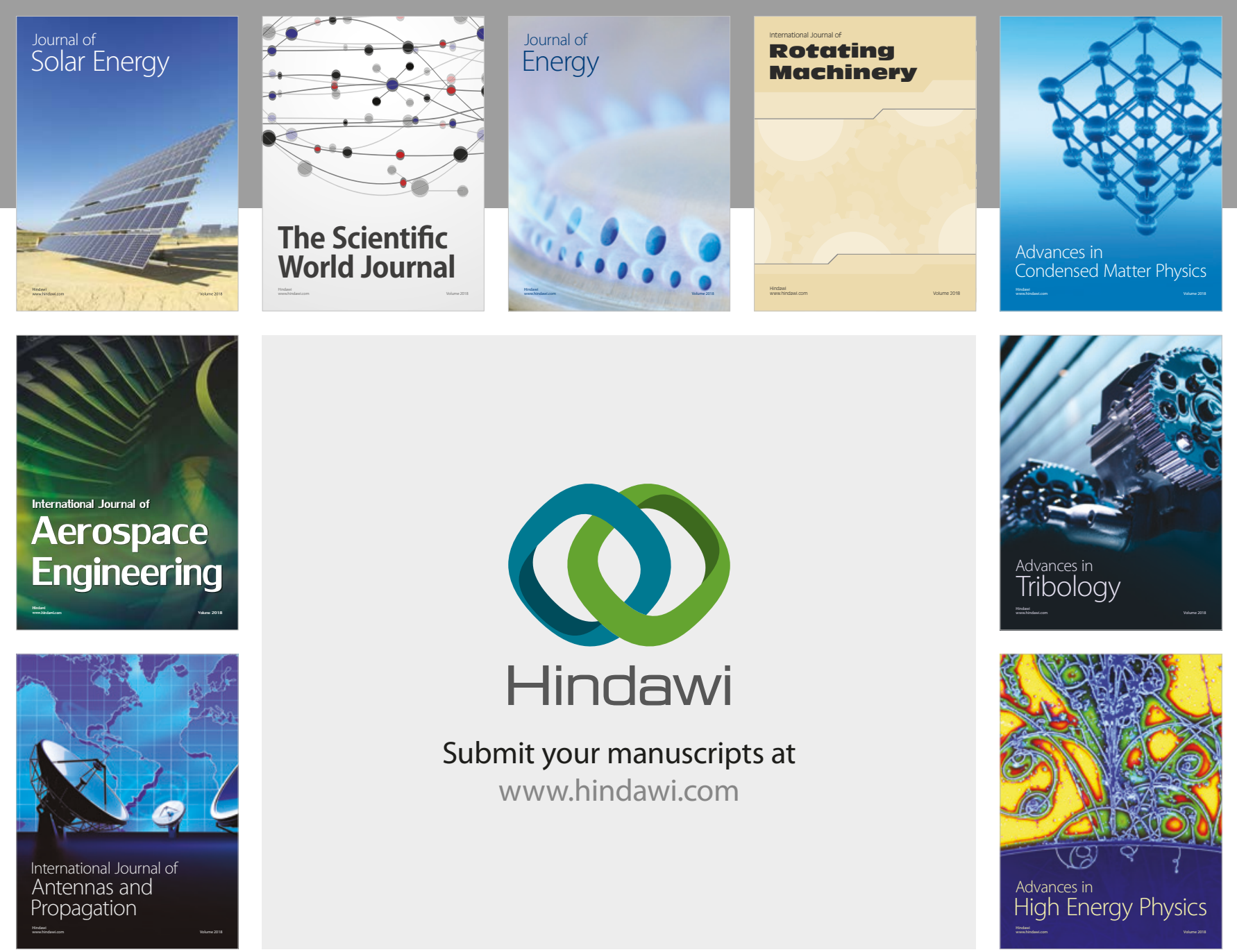

Submit your manuscripts at

www.hindawi.com
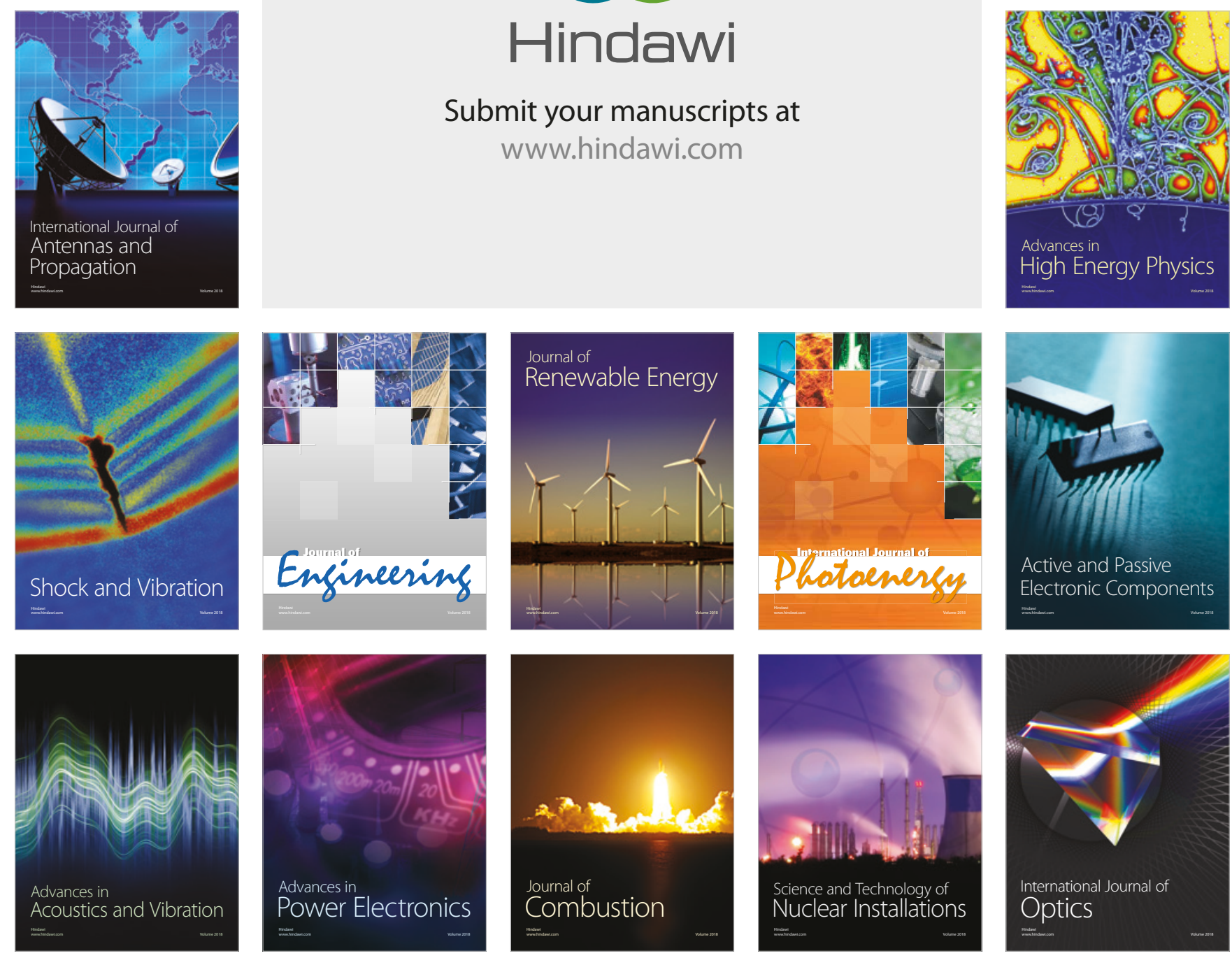